\title{
Evidence that entry into sporulation in Bacillus subtilis is governed by a gradual increase in the level and activity of the master regulator Spo0A
}

\author{
Masaya Fujita and Richard Losick ${ }^{1}$ \\ Department of Molecular and Cellular Biology, Harvard University, Cambridge, Massachusetts 02138, USA
}

\begin{abstract}
The transcription factor Spo0A is a master regulator for entry into sporulation in the bacterium Bacillus subtilis, but it has been uncertain whether activation of Spo0A is sufficient to trigger development. Spo0A, a member of the response regulator family of gene-control proteins, is activated by phosphorylation via a multicomponent phosphorelay in response to conditions of nutrient limitation. We now report that sporulation can be triggered with high efficiency in cells in the exponential phase of growth in rich medium by artificial induction of the synthesis of any one of three histidine kinases that feed phosphoryl groups into the relay. We further show that the levels of Spo0A protein and activity increase gradually over the first $\mathbf{2} \mathrm{h}$ of sporulation both under conditions of nutrient limitation and in response to induction of kinase synthesis. Evidence indicates that this gradual increase in Spo0A protein and activity plays a critical role in triggering sporulation and requires the action of the phosphorelay.
\end{abstract}

[Keywords: Bacillus subtilis; sporulation; development; response regulator; transcription; phosphorelay]

Supplemental material is available at http://www.genesdev.org.

Received May 23, 2005; revised version accepted July 11, 2005.

A central challenge in developmental biology is to elucidate the regulatory events that cause cells to enter a pathway of differentiation. This requires an understanding of both what is necessary and what is sufficient to trigger differentiation. An attractive system in which to address this challenge is the process of sporulation by the bacterium Bacillus subtilis (Stragier and Losick 1996; Piggot and Losick 2002). Sporulating cells of B. subtilis proceed through a $7-8-\mathrm{h}$ program of development that culminates in the formation of a spore (more properly, an endospore). Among the principal morphological features of this process are (in sequence) remodeling of chromosomes into a filament; asymmetric division, which divides the cell into forespore and mother-cell compartments; engulfment of the forespore by the mother cell; maturation of the developing (fore)spore; and, finally, release of the ripened spore by lysis of the mother cell (Stragier and Losick 1996; Piggot and Losick 2002).

Entry into the sporulation pathway is governed by a member of the response regulator family of transcription factors known as Spo0A (Hoch 1993). Like other response regulators, SpoOA is activated by phosphorylation on an aspartyl residue located in the $\mathrm{N}$-terminal portion

${ }^{1}$ Corresponding author.

E-MAIL losick@mcb.harvard.edu; FAX (617) 496-4642.

Article and publication are at http://www.genesdev.org/cgi/doi/10.1101/ gad. 1335705 . of the protein. Phosphorylation stimulates the capacity of SpoOA to bind to its recognition sequence in DNA, known as the 0A-box via its DNA-binding domain, which is located in the C-terminal portion of the protein (Stephenson and Hoch 2002). Most response regulators are phosphorylated directly by a cognate sensor kinase that carries out autophosphorylation on a histidine residue and then transfers the phosphoryl group to the aspartyl residue in the response regulator. Spo0A, in contrast, is indirectly phosphorylated by a multicomponent phosphorelay involving at least three kinases called KinA, KinB, and KinC (Stephenson and Hoch 2002). The kinases phosphorylate SpoOF, and the resulting SpoOF $\sim$, in turn, transfers the phosphoryl group to SpoOB. Finally, Spo0B $\sim$ transfers the phosphoryl group to, and thereby activates, Spo0A (Burbulys et al. 1991). Conversely, phosphoryl groups are drained from the relay by the action of dedicated phosphatases that dephosphorylate SpoOF P and Spo0A P (Perego and Hoch 2002). The opposing action of the kinases and the phosphatases is believed to integrate environmental and physiological signals in the decision to sporulate by governing flux through the relay and hence the level of Spo0A $\sim$, which must reach a threshold concentration to trigger sporulation (Fujita et al. 2005). Spo0A is additionally subject to control at the levels of its synthesis and activity by a positive feedback loop in which the response regulator stimulates the synthesis of the RNA polymerase $\sigma$ factor 
$\sigma^{\mathrm{H}}$, which, in turn, stimulates transcription of the gene for SpoOA as well as the genes for the phosphorelay components KinA and SpoOF (Hoch 1991). Although SpoOA is traditionally recognized for its role in governing the initiation phase of sporulation, recent work indicates that the response regulator continues to function at intermediate stages of sporulation, when it accumulates to high levels and directs transcription in the mother cell (Fujita and Losick 2003).

Genomic and biochemical experiments in combination with bioinformatics reveal $\sim 120$ genes that are under the direct control of Spo0A (Molle et al. 2003a). Interestingly, the regulon largely consists of two categories of genes with respect to their responsiveness to Spo0A: those that are activated or repressed at a low dose of the Spo0A P (low-threshold genes) and those that require a high dose to be turned on or off (high-threshold genes) (Fujita et al. 2005). Genes that are directly involved in sporulation generally fall in the high-threshold category, whereas genes that are involved in auxiliary processes, such as cannibalism (Gonzalez-Pastor et al. 2003) and fruiting body formation (Branda et al. 2001) largely fall in the low-threshold category. This has led to the idea that the level of Spo0A P increases progressively in response to conditions of nutrient limitation with low-threshold genes switching on or off earlier than high-threshold genes (Fujita et al. 2005).

In sum, a large body of evidence indicates that Spo0A $\sim \mathrm{P}$ is a master regulator that is necessary for entry into sporulation. But is Spo0A P sufficient to trigger development? If the answer to this question is yes, then it should be possible to bypass the usual nutritional signals that govern entry into sporulation by inducing the synthesis and activation of the master regulator in cells growing in rich medium. However, cells engineered to produce a mutant form of Spo0A (Spo0A-Sad67) that is locked in an activated state (independently of being phosphorylated) sporulate poorly even though they express genes in the Spo0A P regulon at high levels (Ireton et al. 1993). We wondered whether this failure reflected an as yet unrecognized feature of how Spo0A P triggers development. Here we report that rapid and efficient induction of sporulation in the presence of excess nutrients can be achieved by artificial activation of the phosphorelay during the exponential phase of growth. We propose that the phosphorelay is part of a mechanism that causes the level and activity of Spo0A to increase in a gradual manner, thereby allowing early-threshold genes to switch on or off earlier than high-threshold genes. We further propose that the successive activation (and/or repression) of low- and high-threshold genes plays a critically important role in unleashing development.

\section{Results}

An activated form of SpoOA fails to trigger sporulation during growth

We began our investigation by asking whether we could trigger sporulation in growing cells by engineering the synthesis of an activated form of Spo0A. For this purpose, we used a mutant of Spo0A called Spo0A-Sad67 (henceforth Spo0A*) (Ireton et al. 1993) that is locked in an active state due to a short internal truncation. SpoOA* does not depend on phosphorylation to be active and hence bypasses the usual requirement for the phosphorelay in turning on gene transcription. To engineer the synthesis of $\mathrm{SpoOA}^{\star}$ during growth we used a fusion of the deletion-mutated gene to the IPTG-inducible promoter $\mathrm{P}_{\text {hyper-spank }}$ (a gift from D. Rudner, Harvard Medical School, Boston, MA; Britton et al. 2002), which, for simplicity, is hereafter referred to as $\mathrm{P}_{\text {hy-spank. }}$. Synthesis of Spo0A* was switched on at the mid-exponential phase of growth $\left(\mathrm{OD}_{600}=0.4\right)$ in $\mathrm{CH}$ medium (a rich medium for which casein hydrolysate is the sole carbon source) by the addition of IPTG. The results of Figure 1C show that by $2.5 \mathrm{~h}$ after the addition of inducer to cells harboring the $\mathrm{P}_{\text {hy-spank }}$-spoOA* construct, the level of transcription (as monitored by use of a lacZ fusion) from a promoter (that for the spoIIG operon) known to be under the direct control of Spo0A was similar to that observed $2.5 \mathrm{~h}$ after the start of development by suspension in Sterlini-Mandelstam (SM) medium (a sporulation medium lacking any carbon source except glutamate) (Sterlini and Mandelstam 1969). Nevertheless, entry into sporulation as judged by the appearance of cells with an asymmetrically positioned (polar) septum, an early morphological manifestation of spore formation, was much lower $(5 \%$; Fig. $1 \mathrm{~A}, \mathrm{~B})$ in cells engineered to produce Spo0A ${ }^{\star}$ during growth than that observed $(52 \%)$ in wildtype cells in SM medium. Thus, even though we were able to achieve a high level of $\mathrm{SpoOA}{ }^{\star}$-directed gene expression in cells growing in $\mathrm{CH}$ medium, only a small proportion of the cells progressed to an early stage of sporulation.

Spo0A accumulates gradually at the start of sporulation

A possible explanation for the failure of the $\mathrm{P}_{h y-\text { spank }^{-}}$ $s p o 0 A^{*}$ construct to trigger efficient sporulation came from immunoblot analysis of the accumulation of the developmental regulatory protein. The time-course experiment in Figure 2B shows that the final level of accumulation of SpoOA* during the growth of engineered cells in $\mathrm{CH}$ medium (second set of blots from bottom) was similar to that of SpoOA under normal sporulation conditions in SM medium (top set of blots). However, the rate of accumulation of $\mathrm{SpoOA}{ }^{\star}$ was much more rapid than that observed for SpoOA during sporulation, which accumulated gradually over a 2-h period. Figure $2 \mathrm{~B}$ shows that the accumulation of SpoOA was similarly abrupt in cells engineered to produce the wild-type regulatory protein in response to IPTG (third set of blots from bottom). We therefore hypothesized that the normal mode of activating SpoOA via the phosphorelay is responsible for allowing SpoOA to accumulate in a gradual manner, and that this slow accumulation plays a critical role in the ability of the regulatory protein to trigger sporulation. 


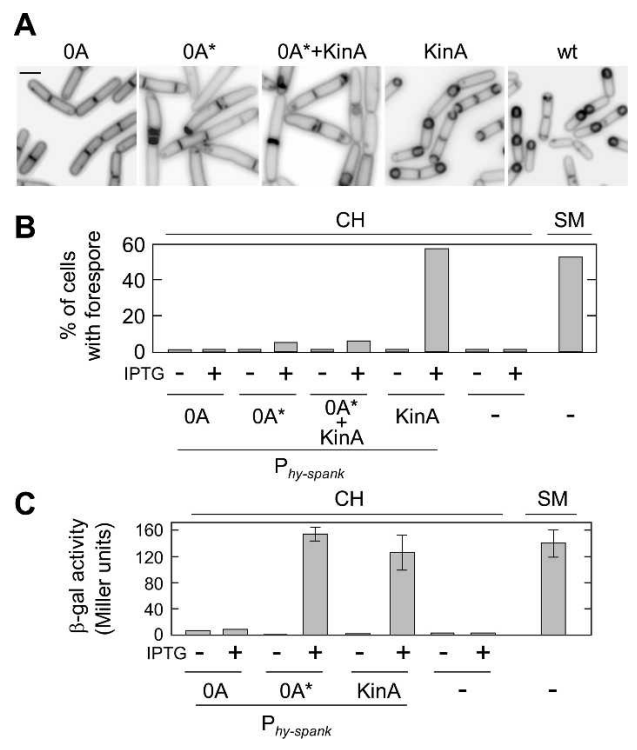

Figure 1. Triggering efficient sporulation by artificial induction of KinA synthesis. $(A)$ Forespore formation. Cells of strains MF2001 ( $\mathrm{P}_{\text {hy-spank }}$-spo0A), MF2146 ( $\mathrm{P}_{\text {hy-spank }}$-spo0A* ${ }^{*}$, MF2252 $\left(\mathrm{P}_{\text {hy-spank }}\right.$-kinA, $\mathrm{P}_{\text {hy-spank }}$-spoOA* ${ }^{*}$, and $\mathrm{MF1887}\left(\mathrm{P}_{\text {hy-spank }}\right.$-kinA $)$ were grown in $\mathrm{CH}$ medium and treated with IPTG $(20 \mu \mathrm{M}$ for MF1887, and $200 \mu \mathrm{M}$ for MF2001, MF2146, and MF2252) at the mid-exponential phase of growth. Cells of the wild-type strain PY79 (wt) were suspended in SM sporulation medium. Cells were treated with the vital membrane stain FM4-64 at hour 3 after suspension in SM medium for strain PY79 (wt) or after treatment with inducer for the strains harboring IPTG-inducible constructs, and observed by fluorescence microscopy. IPTG was used at concentrations determined in immunoblot experiments to yield levels of KinA and Spo0A that corresponded to that observed in wild-type cells undergoing sporulation in response to nutrient limitation. Bar, $2 \mu \mathrm{m}$. (B) Analysis of sporulation. The percentage of sporangia with a forespore, as judged from FM4-64 staining as in $A$, was determined for strains engineered to produce the indicated proteins at hour 3 after the addition of inducer. Also shown as controls are the results with the wild-type strain PY79 (right-most three bars). (C) Transcription from a Spo0A-dependent promoter. The accumulation of $\beta$-galactosidase from a $\mathrm{P}_{\text {spoII }}-1$ lac $Z$ fusion was monitored as a measure of Spo0A activity. Cells of strains MF2175 ( $\mathrm{P}_{\text {hy-spank }}{ }^{-}$ spo0A), MF2176 ( $\mathrm{P}_{\text {hy-spank }}$-spoOA* $\left.{ }^{*}\right), \operatorname{MF} 1917\left(\mathrm{P}_{\text {hy-spank }}\right.$-kinA), and MF290 (-), which each contained $\mathrm{P}_{\text {spoII }}-1 a c Z$, were induced to sporulate as described in $A$. $\beta$-Galactosidase activity was measured at hour 2.5 after the addition of inducer for the strains harboring IPTG-inducible constructs or after suspension in SM medium for strain MF290. The average of three independent results is shown, with the error bars indicating the standard deviation.

\section{Inducing the synthesis of KinA during growth triggers efficient sporulation}

To investigate this possibility, we attempted to activate the phosphorelay in growing cells by inducing the synthesis of a kinase, Kinase A (KinA), that is known to feed phosphoryl groups into the relay. For this purpose, we used a fusion of the gene for KinA to the IPTG-inducible, $\mathrm{P}_{\text {hy-spank }}$ promoter. The results in Figure 1C show that the addition of IPTG to cells harboring the $\mathrm{P}_{\text {hy-spank }}{ }^{-}$ kin $A$ construct led to a high level of $\beta$-galactosidase synthesis from the $\mathrm{P}_{\text {spoIIG }}-1 a c Z$ fusion. In striking contrast to the results seen with the $\mathrm{P}_{\text {hy-spank }}-$ spo0 $A^{*}$ construct (above), however, the induction of the kin $A$ gene at the mid-exponential phase of growth in $\mathrm{CH}$ medium led to the appearance of many cells (57\% of the population) that contained a polar septum (Fig. 1A,B). For comparison, only a low percentage $(0.7 \%$; Fig. $1 \mathrm{~B})$ of cells harboring the $\mathrm{P}_{\text {hy-spank }}-$ kin $A$ construct produced polar septa in the absence of added inducer. The percentage of cells exhibiting a polar septum was similarly small $(0.4 \%$; Fig. 1B) when wild-type cells (that is, cells lacking the construct) were grown in $\mathrm{CH}$ medium.

Extending the analysis further, a time-course experiment demonstrated that the appearance of sporangia that had undergone asymmetric division and the subsequent
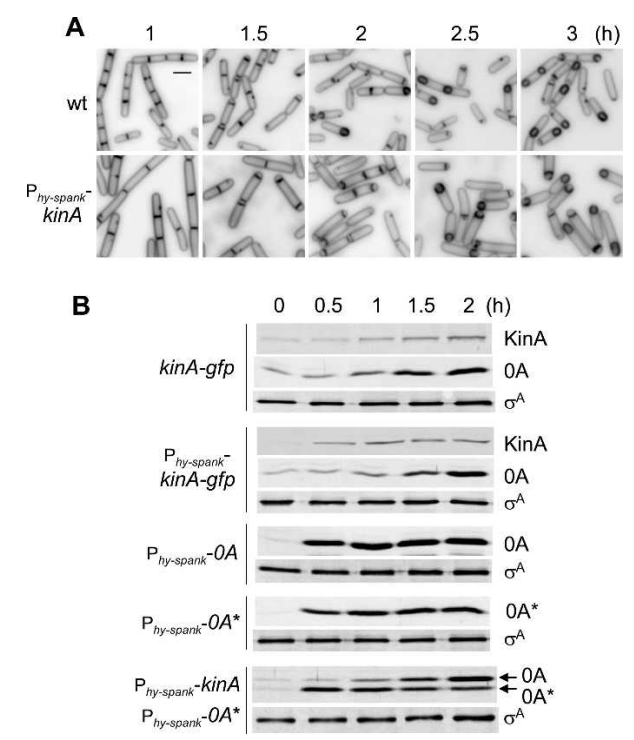

Figure 2. Comparative timing of sporulation in response to nutrient limitation and induced synthesis of KinA. (A) Sporulation was induced in response to nutrient limitation by cells of the wild-type strain PY79 in SM medium (upper panels) or in response to KinA synthesis by cells of strain MF1887 ( $\mathrm{P}_{\text {hy-spank }}{ }^{-}$ kinA) in $\mathrm{CH}$ medium (lower panels). Samples were collected at the indicated times following suspension in SM medium (upper panels) or after the addition of IPTG (lower panels). The cells were treated with the membrane stain FM4-64 and examined by fluorescence microscopy. Bar, $2 \mu \mathrm{m}$. (B) Accumulation of KinA and Spo0A in cells of a strain (MF928; kinA-gfp) in which KinA was tagged with GFP and produced under its normal promoter and a strain (MF1996; $\mathrm{P}_{\text {hy-spank }}$-kinA-gfp) in which GFP-tagged KinA was produced under the control of an IPTG-inducible promoter. Also shown are the accumulation of SpoOA and SpoOA* in the IPTG-inducible strains MF2001 ( $\mathrm{P}_{\text {hy-spank }}-$ spo0A), MF2146 ( $\mathrm{P}_{\text {hy-spank }}$-spoOA* ${ }^{*}$, and MF2252 $\left(\mathrm{P}_{\text {hy-spank }}-k i n A, \mathrm{P}_{h y-}\right.$ spank-spoOA*). Samples were collected at the indicated times after suspension in SM medium for the wild-type strain or after the addition of IPTG for all other strains and analyzed by immunoblotting using anti-GFP antibodies for KinA-GFP, and with anti-SpoOA antibodies for SpoOA and Spo0A*. The anti- $\sigma^{\mathrm{A}}$ immunoblot served as a loading control. 
stage of engulfment in response to artificial induction of KinA synthesis in $\mathrm{CH}$ medium (images across the bottom of Fig. 2A) was approximately as rapid as that normally observed during sporulation with wild-type cells that had been transferred to SM medium (images across the top of Fig. 2A). Thus, $\sim 30 \%$ of the population exhibited polar septa both at $1.5 \mathrm{~h}$ after the addition of inducer to $\mathrm{P}_{\text {hy-spank }}$-kinA-harboring cells growing in $\mathrm{CH}$ medium and at $1.5 \mathrm{~h}$ after the transfer of wild-type cells to SM medium. Likewise, under both conditions, the proportion of cells with polar septa increased to $\sim 50 \%$ by hour 2.5. Finally, by hour 3, sporangia that had undergone engulfment could be observed as readily in engineered cells as in cells in sporulation medium.

Next, we carried out an immunoblot analysis to visualize the accumulation of Spo0A in cells engineered to produce KinA during growth. The results in Figure 2B show that the rate of accumulation of the master regulator in $\mathrm{P}_{\text {hy-spank }}$-kinA-harboring cells growing in $\mathrm{CH}$ medium (second set of blots from the top) was similar to that observed under normal sporulation conditions in SM medium (top set of blots). For comparison, Figure 2B shows that KinA (as monitored using a functional fusion to GFP and anti-GFP antibodies) accumulated to similar levels under both sets of conditions (although more abruptly in the case of the engineered cells). We conclude that artificially inducing the synthesis of KinA during growth caused SpoOA to accumulate in a manner that closely mimicked the normal time course of accumulation of the regulatory protein.

Finally, we investigated whether KinA was acting through the phosphorelay in our engineered cells. When mutations in the phosphorelay genes spoOF or $s p o O B$ were introduced into cells harboring the $\mathrm{P}_{\text {hy-spank }}-\mathrm{kin} A$ construct, the capacity of the cells to activate transcription of the $\mathrm{P}_{\text {spoII }}-1$ ac $Z$ fusion during growth on $\mathrm{CH}$ medium was prevented (data not shown), in keeping with the idea that KinA was exerting its effect in a phosphorelay-dependent manner.

\section{Engineered synthesis of KinA* causes a dominant-negative phenotype}

If, as we propose, Spo0A must accumulate in a gradual manner in order for sporulation to be triggered efficiently, then we would expect that inducing the synthesis of both SpoOA* and KinA during growth would block sporulation. That is, IPTG-treatment of cells containing the $\mathrm{P}_{\text {hy-spank-spoOA* }}$ construct as well as the $\mathrm{P}_{\text {hy-spank }}{ }^{-}$ $\operatorname{kin} A$ construct should be ineffective in triggering sporulation. In keeping with this prediction, the results in Figure 1B show that cells simultaneously harboring both constructs underwent asymmetric division no more effectively than did cells harboring the $\mathrm{P}_{\text {hy-spank }}$-spoOA* construct alone and much less effectively than did cells harboring the $\mathrm{P}_{h y-\text { spank }}-k i n A$ construct alone. In other words, Spo0A* exerted a "dominant-negative" effect on sporulation. Also, and importantly, the immunoblot results in Figure 2B show that Spo0A* (which due to the internal truncation is slightly smaller than the wild-type response regulator) accumulated more rapidly than did Spo0A in the cells harboring both $\mathrm{P}_{h y-\text { spank }}-$ spoOA* ${ }^{*}$ and $\mathrm{P}_{\text {hy-spank }}$-kinA (bottom set of blots).

\section{Induced synthesis of KinA triggers nucleoid remodeling and compartment-specific gene expression}

To assess further the fidelity of KinA-induced sporulation during growth in $\mathrm{CH}$ medium, we investigated whether the nucleoid underwent remodeling into an elongated "axial filament," an early morphological manifestation of sporulation (Ben-Yehuda et al. 2003), and whether we could observe compartment-specific gene transcription. The results in Supplementary Figure S1 show that the chromosomes underwent conversion (in an IPTG-dependent manner) from two separate and compact DNA masses, as characteristically observed in vegetative cells, into a single, elongated filament that stretched from cell pole to cell pole. Supplementary Figure S1 also shows an example of a sporangium (on the left side of the +IPTG column) in which a polar septum had formed, thereby trapping the end of the axial filament in the newly formed forespore.

To visualize compartment-specific gene expression, we used fusions of $g f p$ to promoters for genes known to be under the control of the intermediate-stage $\sigma$ factors $\sigma^{\mathrm{F}}\left(\right.$ spoIIQ) and $\sigma^{\mathrm{E}}\left(\right.$ spoIID), and the late-stage $\sigma$ factor $\sigma^{\mathrm{K}}$ (gerE). For comparison, we used a kinA-gfp fusion, which is expressed prior to the formation of mother-cell and forespore compartments. As seen in Figure 3A, green fluorescence from the kinA-gfp fusion was readily detected throughout the sporangium following the addition of IPTG to $\mathrm{P}_{\text {hy-spank }}$-kinA-containing cells growing in $\mathrm{CH}$ medium, a pattern similar to that observed in cells undergoing sporulation in SM medium. In contrast, GFP produced under the control of the sporulation $\sigma$ factors was confined to the forespore (in the case of $\sigma^{\mathrm{F}}$ when examined at hour 3) or the mother cell (in the case of $\sigma^{\mathrm{E}}$ when examined at hour 3 and in the case of $\sigma^{\mathrm{K}}$ when examined at hour 6), spatial patterns that closely mimicked those seen under normal conditions of sporulation. Notice that by hour 6 many of the forespores had metamorphosed into phase-bright, nascent spores in both the cells that had been artificially induced to sporulate with $\mathrm{P}_{\text {hy-spank }}$-kinA and in otherwise wild-type cells undergoing sporulation in SM medium.

Reinforcing our findings (above) that engineered production of Spo0A* or wild-type Spo0A during growth fails to trigger sporulation, addition of IPTG to cells harboring $\mathrm{P}_{\text {hy-spank }}$-spoOA* or $\mathrm{P}_{\text {hy-spank }}-$ spoOA failed to activate $\sigma^{\mathrm{K}}$-directed GFP synthesis or the production of phase-bright prespores (Fig. 3B). The quantitative analysis in Figure 3C, which was based on the use of lacZ fused to the promoter for the $\sigma^{\mathrm{K}}$-controlled gerE gene, shows that IPTG-induced synthesis of KinA was markedly more effective in activating $\sigma^{\mathrm{K}}$ than was the induced synthesis of SpoOA or SpoOA*. Also, and as expected, little $\sigma^{\mathrm{K}}$ activity was observed when cells lacking the $\mathrm{P}_{\text {hy-spank }}$ constructs were grown in $\mathrm{CH}$ medium.

In toto, our results indicate that artificial induction of 

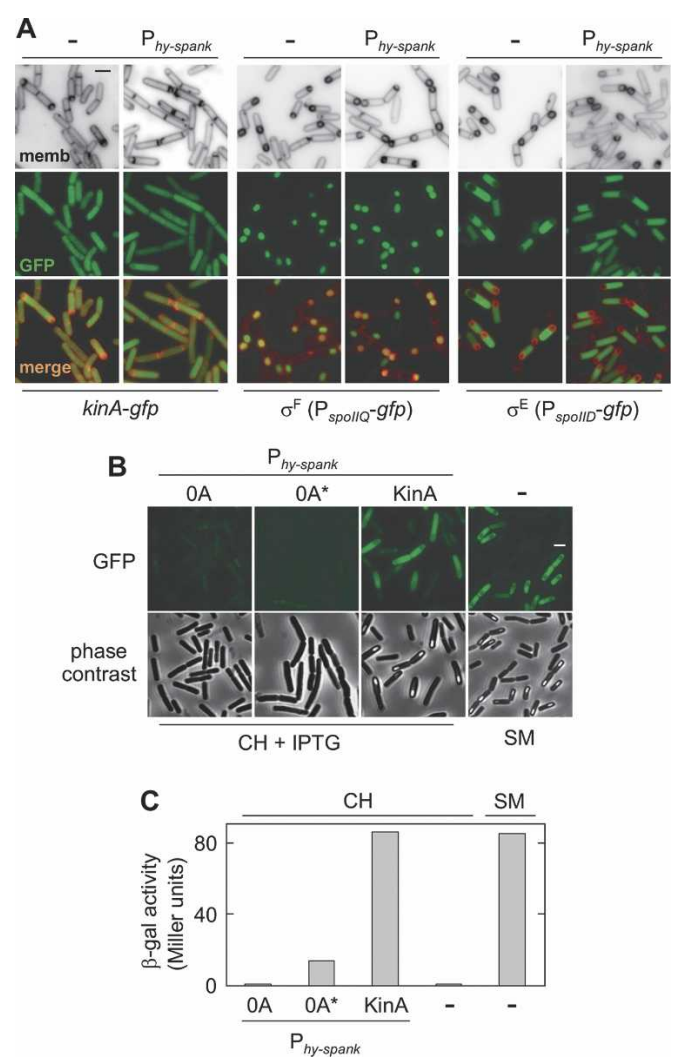

Figure 3. Compartment-specific gene expression in response to the induction of KinA synthesis. (A) Accumulation of KinAGFP and compartment-specific synthesis of GFP produced under the control of $\sigma^{\mathrm{F}}\left(\mathrm{P}_{\text {spoIIQ }}-g f p\right)$ and $\sigma^{\mathrm{E}}\left(\mathrm{P}_{\text {spoIID }}-g f p\right)$ during sporulation. Cells of strains MF1996 $\left(\mathrm{P}_{\text {hy-spank }}-k i n A-g f p\right)$, MF1956 ( $\mathrm{P}_{\text {hy-spank }}-$ kinA, $\mathrm{P}_{\text {spoIIQ }}$-gfp $)$, and MF1957 $\left(\mathrm{P}_{\text {hy-spank }}{ }^{-}\right.$ $\operatorname{kin} A, \mathrm{P}_{\text {spoIID }}-g f p$ ) were induced to sporulate by addition of IPTG in CH medium. Cells of strains MF928 (-, kinA-gfp), PE128 (-, $\left.\mathrm{P}_{\text {spoIIQ }}-g f p\right)$, and MF248 (-, $\left.\mathrm{P}_{\text {spoIID }}-g f p\right)$ were induced to sporulate in SM medium as controls. The production of GFP was monitored by fluorescence microscopy at hour 1.5 for KinA-GFP and at hour 3 for $\mathrm{P}_{\text {spoIIQ }}$-gfp and $\mathrm{P}_{\text {spoIID- }}-g f p$ after induction of sporulation. The cells were also visualized by staining with FM4-64. Bar, $2 \mu \mathrm{m}$. (B) Compartment-specific synthesis of GFP produced under the control of the mother-cell regulatory protein $\sigma^{\mathrm{K}}$. Cells of strains MF2238 ( $\mathrm{P}_{\text {hy-spank }}$-spo0A, $\mathrm{P}_{\text {gerE }}$-gfp), MF2239 ( $\mathrm{P}_{\text {hy }}$ spank-spo0A* $\left.\mathrm{P}_{\text {gerE }}-g f p\right)$, and MF2035 ( $\mathrm{P}_{\text {hy-spank }}-k i n A, \mathrm{P}_{\text {gerE }}$-gfp $)$ were induced to sporulate by addition of IPTG in $\mathrm{CH}$ medium. Cells of strain EG180 (-, $\left.\mathrm{P}_{g e r E^{-}} g f p\right)$ were induced to sporulate in SM medium as a control. The production of GFP was monitored by fluorescence microscopy at hour 6 after induction of sporulation. The cells were also observed by phase-contrast microscopy to detect phase-bright forespores. Bar, $2 \mu \mathrm{m}$. $(C)$ Accumulation of $\beta$-galactosidase in cells harboring a fusion $\left(\mathrm{P}_{\text {gerE }}-1 a c Z\right)$ of $l a c Z$ to a promoter under the control of $\sigma^{\mathrm{K}}$. Cells of strain MF2243 ( $\mathrm{P}_{\text {hy-spank }}$-spoOA), MF2244 ( $\mathrm{P}_{\text {hy-spank }}$-spoOA $\left.{ }^{*}\right)$, MF2242 $\left(\mathrm{P}_{\text {hy-spank }}-\mathrm{kin} A\right)$, and MF2240 (-), which each contained $\mathrm{P}_{\text {gerE }}{ }^{-}$ $1 a c Z$, were induced to sporulate as described in $B$. $\beta$-Galactosidase activity was measured at hour 6 after induction of sporulation.

KinA synthesis during growth is capable of triggering the normal repertoire of developmental events characteristic of sporulation during nutrient limitation.

\section{KinA is effective in triggering rapid sporulation early in exponential-phase growth}

We also investigated whether the $\mathrm{P}_{\text {hy-spank }}-k i n A$ construct would be effective in triggering sporulation at both early and late times in the exponential phase of growth. The results in Figure 3 show that the addition of IPTG at low $\left(\mathrm{OD}_{600}=0.05\right)$ or high $\left(\mathrm{OD}_{600}=0.5\right)$ cellpopulation densities led to similar patterns of induction (relative to the time of addition of inducer) of lac $Z$ fused to the early-activated sporulation gene spoIIG (Fig. 4B), the intermediate-stage gene spoIID (Fig. 4C), and the late-stage gene gerE (Fig. 4D). In contrast, only a low level of $\beta$-galactosidase activity was detected when inducer was omitted. Interestingly, treatment with IPTG at the low cell-population density led to a marked decrease in the growth rate after a delay of $\sim 2 \mathrm{~h}$ (Fig. $4 \mathrm{~A}$ ). We interpret this decrease in growth rate as being due to the KinA-induced entry of the cells into sporulation.

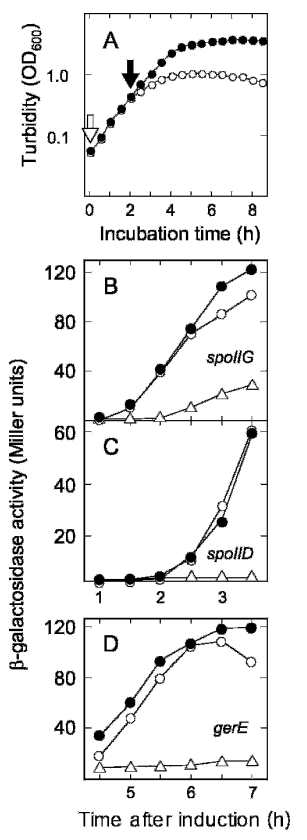

Figure 4. Induction of KinA synthesis triggers sporulation early in the exponential phase of growth. $(A)$ Effect of inducing KinA synthesis on the growth rate of cells of strain MF1913 $\left(\mathrm{P}_{\text {hy-spank }}\right.$-kinA $)$ growing in $\mathrm{CH}$ medium. IPTG was added at $\mathrm{OD}_{600}=0.05$ (open arrow and open circles) and 0.5 (filled arrow and filled circles). Cell growth was followed by turbidity measurements $\left(\mathrm{OD}_{600}\right)$. $(B-D)$ Accumulation of $\beta$-galactosidase was measured in strains harboring lacZ fused to the indicated promoters in kinA-inducible strains. Samples were collected at the indicated times after the addition of IPTG. Culture conditions and symbols are as in $A$. The fusions of lac $Z$ were to the promoters for the following genes: spoIIG $(B)$, which is under the control of Spo0A (strain MF1917); spoIID (C), which is under the control of the intermediate-stage regulatory protein $\sigma^{\mathrm{E}}$ (strain MF2210); and gerE (D), which is under the control of the late-stage regulatory protein $\sigma^{\mathrm{K}}$ (strain MF2242). Accumulation of $\beta$-galactosidase in the absence of inducer in each strain was also examined (open triangles). 
Gradual accumulation of SpoOA causes sequential activation of low- and high-threshold genes

How are we to explain the much greater effectiveness of KinA compared with SpoOA* in triggering sporulation? In earlier work we distinguished between genes that are activated (or repressed) at a low level of Spo0A P (lowthreshold genes) and genes that require a high level of the transcription factor in order to be switched on (or off) (Fujita et al. 2005). We further observed that low-threshold genes are activated (or repressed) earlier than highthreshold genes. We therefore hypothesized that entry into sporulation requires a gradual increase in the level and activity of the master regulator and that this is normally achieved through the action of the phosphorelay acting in concert with the positive feedback loop that stimulates synthesis and phosphorylation of Spo0A. Thus, in the context of our present experiments, we hypothesize that induction of KinA synthesis led to a gradual increase in Spo0A-directed gene expression whereas induction of Spo0A* synthesis led to an acute increase in the expression of genes under Spo0A control.

As a test of this hypothesis we examined the timing of activation of a representative low-threshold gene (skf) and a representative high-threshold gene (spoIIG) under the two conditions. As can be seen in the fluorescence microscopy experiment in Figure 5, when sporulation was triggered using the $\mathrm{P}_{\text {hy-spank }}-$ kinA construct, GFP from the low-threshold gene was seen at both an early (hour 1.5) and a later time (hour 3) after the start of sporulation, whereas GFP from the high-threshold gene was only seen at the later time, results that closely mimicked the situation in wild-type cells undergoing sporulation under nutrient-limitation conditions. In sharp contrast, in cells harboring the $\mathrm{P}_{\text {hy-spank }}-s p o 0 A^{*}$ construct, GFP from both the low-threshold and the high-threshold genes was seen at the early time after the addition of inducer.

This difference in timing was also seen when the time course of gene activation was measured using lac $Z \mathrm{fu}-$ sions. As shown in Supplementary Figure S2B, the time course of $\beta$-galactosidase accumulation from the lowthreshold gene fusion was indistinguishable between cells in which SpoOA* synthesis was induced and cells in which KinA synthesis was induced. In the case of the high-threshold gene, in contrast, induction of Spo0A* synthesis led to more rapid activation of the high-threshold gene than did induction of KinA synthesis (Supplementary Fig. S2C). Thus, the induction of KinA synthesis most closely resembled the situation in wild-type cells undergoing sporulation in SM medium, where activation of the low-threshold gene occurred earlier than activation of the high-threshold gene (Supplementary Fig. 2A).

\section{Induced synthesis of KinA, KinB, or KinC triggers sporulation}

KinA is a member of a family of five related histidine kinases, all of which are potentially capable of phos-

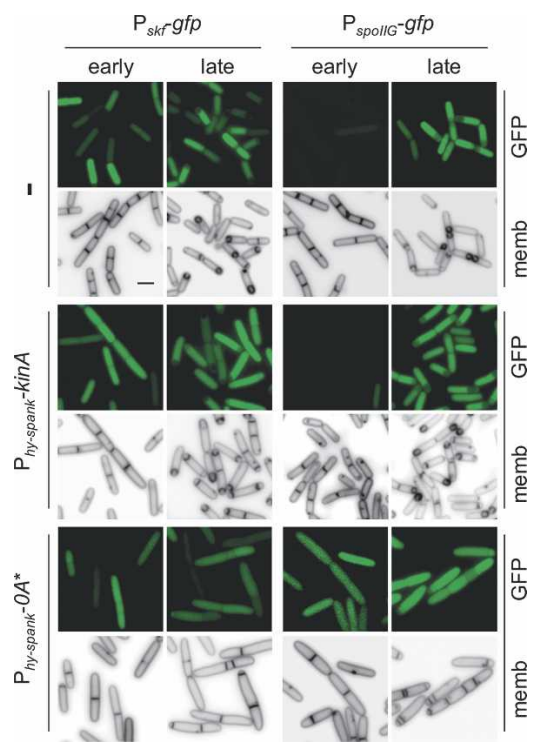

Figure 5. Relative timing of transcription from low- and highthreshold promoters as monitored by use of $g f p$ fusions. Shown are fluorescence images obtained with cells of wild-type, KinAinducible, and Spo0A*-inducible strains that each contained a fusion of $g f p$ to the low-threshold promoter $\mathrm{P}_{s k f}$ or to the highthreshold promoter $\mathrm{P}_{\text {spoIIG. }}$. Cells were induced to sporulate in SM medium (in the case of the wild type) or by IPTG addition in $\mathrm{CH}$ medium for the strains harboring IPTG-inducible constructs. The production of GFP was monitored by fluorescence microscopy at hour 1.5 (early) and at hour 3 (late) after induction of sporulation. Strains: EG297 (-, $\left.\mathrm{P}_{s k f} g f p\right)$, MF237 (-, $\mathrm{P}_{\text {spoIIG }}{ }^{-}$ $g f p), \operatorname{MF} 1959\left(\mathrm{P}_{\text {hy-spank }}-k i n A, \mathrm{P}_{\text {skf }}-g f p\right)$, MF1929 $\left(\mathrm{P}_{\text {hy-spank }}-k i n A\right.$,

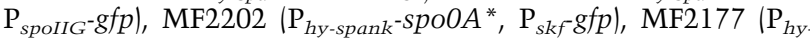
spank-spo0A*, $\left.\mathrm{P}_{\text {spoIIG }}-g f p\right)$. The cells were also visualized by treatment with the vital membrane stain FM4-64. Bar, $2 \mu \mathrm{m}$.

phorylating the single-domain response regulator SpoOF and relaying phosphate to Spo0A (Fabret et al. 1999). We wondered whether SpoOF is a true substrate for all five kinases (KinA, KinB, KinC, KinD, and KinE) under sporulation conditions. To address this issue, we created strains engineered to produce each of the kinases in response to IPTG using the IPTG-inducible promoter. As shown in Figure 6, induction of KinA, KinB, and KinC synthesis triggered entry into sporulation as judged by the appearance of polar septa and engulfed forespores, but neither KinD nor KinE had a measurable effect in triggering the early morphological events of sporulation. These results raise the possibility that SpoOF is not the physiological substrate for KinD and KinE and that these kinases do not normally feed phosphates into the phosphorelay.

\section{Discussion}

Evidence indicates that Spo0A plays a central role in the initiation of sporulation, but until now it has been unclear whether activation of SpoOA is both necessary and sufficient to trigger development. Indeed, and as documented here, growing cells engineered to produce 


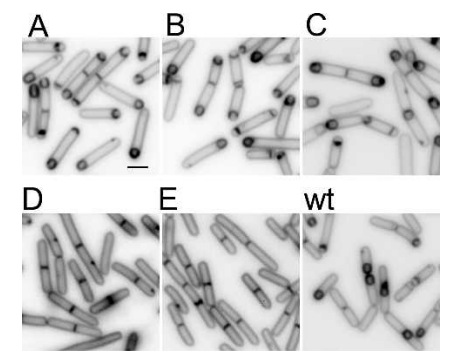

Figure 6. Induced synthesis of KinA, KinB, or KinC, but not of KinD or KinE, triggers sporulation. Cells of strain MF1887 $(A$, $\mathrm{P}_{\text {hy-spank }}-$ kin $\left.A\right), \operatorname{MF} 1888\left(B, \mathrm{P}_{\text {hy-spank }}-k i n B\right), \operatorname{MF1889}$ (C, $\mathrm{P}_{\text {hy- }}$ spank-kinC), MF2147 (D, $\left.\mathrm{P}_{\text {hy-spank }}-k i n D\right), \operatorname{MF} 2148$ (E, $\mathrm{P}_{\text {hy-spank }}{ }^{-}$ kinE), and PY79 (wt) were induced to sporulate in $\mathrm{CH}$ medium followed by IPTG addition or in SM medium [PY79 (wt)]. Cells were treated with the vital membrane stain FM4-64 at hour 3 post-induction and observed by fluorescence microscopy. Bar, $2 \mu \mathrm{m}$.

Spo0A*, which does not depend on phosphorylation in order to be active, fail to sporulate efficiently even though they express genes known to be under the direct control of the master regulator and do so at a high level. A central contribution of our present investigation is the discovery that cells growing in $\mathrm{CH}$ medium can be triggered to sporulate by the synthesis and activation of Spo0A if synthesis and activation are achieved via the phosphorelay. We have shown that cells engineered to produce KinA, a kinase that feeds phosphoryl groups into the phosphorelay, during growth in $\mathrm{CH}$ medium undergo rapid and massive sporulation and do so in a manner that reflects the normal process of sporulation in all respects tested.

Why is it that growing cells engineered to synthesize KinA sporulate with high efficiency whereas cells producing Spo0 ${ }^{*}$ do not? In earlier work, we found that genes under Spo0A P control fall into at least two broad categories: those that are switched on or off at a low dose of Spo0A P and those that are turned on or off at a high dose of the regulator (Fujita et al. 2005). This led us to propose that progressive increases in Spo0A P at the start of sporulation cause low-threshold genes to turn on or off earlier than high-threshold genes. Our present results lead us to conclude that SpoOA protein and activity do indeed increase in a gradual manner at the start of sporulation and that this gradual increase plays a critical role in triggering sporulation.

Four lines of evidence are consistent with these ideas. First, the level of Spo0A protein was observed to increase gradually over the course of the first $2 \mathrm{~h}$ of sporulation under normal conditions of sporulation as well as when sporulation was triggered by induction of KinA synthesis. Second, and as a measure of Spo0A-directed gene expression (Spo0A activity), a low-threshold gene under the control of Spo0A was found to switch on earlier than a high-threshold gene. Third, and in contrast, cells engineered to produce SpoOA* turned on low- and highthreshold genes at about the same time. We interpret this result to indicate that inducing the synthesis of
$\mathrm{SpoOA}^{*}$ results in immediate activation (or repression) of both low- and high-threshold genes. Finally, cells engineered to produce both KinA and Spo0A* were impaired in sporulation. We interpret this result to indicate that acute activation (or repression) of Spo0A-controlled genes interferes with sporulation.

An important implication of our results is that the phosphorelay is part of the mechanism for causing Spo0A and presumably Spo0A P to accumulate in a gradual manner. We have shown that KinA-triggered sporulation depends on the components of the relay, SpoOF and SpoOB, and, as indicated above, synthesis and activation of SpoOA are known to be driven by a positive feedback loop involving the phosphorelay (Predich et al. 1992; Strauch et al. 1993; Fujita and Sadaie 1998). It is generally believed that the phosphorelay is responsible for integrating a variety of environmental and physiological signals into the decision to sporulation (Stragier and Losick 1996; Stephenson and Hoch 2002). We propose that the phosphorelay plays an additional and criti$\mathrm{cal}$ role in a regulatory circuit that causes Spo0A protein and activity to increase in a gradual manner. A key challenge for the future will be to attempt to explain how the positive feedback loop leads to this gradual increase. Another key challenge, if our hypothesis is correct, will be to identify which genes in the Spo0A regulon must be turned on or off later than others in order for morphogenesis to take place.

Our results have a bearing on the role of the GTPbinding protein CodY in the initiation phase of sporulation. CodY is a negatively-acting regulatory protein whose ability to repress is dependent on cellular GTP levels (Ratnayake-Lecamwasam et al. 2001; Sonenshein 2005). When cells are growing in rich medium, cellular GTP levels are high and genes under the control of CodY are repressed. Conversely, when cells are limited for a carbon, nitrogen, or phosphorus source, GTP levels drop, resulting in derepression of CodY-controlled genes. Thus, CodY could contribute to preventing sporulation during growth in rich medium, and indeed among the targets of CodY is spoOA (Molle et al. 2003b). However, our present results show that inducing KinA synthesis during growth in $\mathrm{CH}$ medium overrides the contribution of CodY to the repression of genes that play a critical role in sporulation. Nonetheless, we have observed that entry into sporulation in response to induced synthesis of KinA was significantly delayed under conditions in which the medium $(\mathrm{CH})$ was supplemented with glucose (Supplementary Fig. S3). Furthermore, this delay was eliminated when the cells were mutant for CodY (Supplementary Fig. S3). It is known from previous work that GTP reaches particularly high levels under conditions of glucose supplementation (Lopez et al. 1979, 1980). We conclude that nutritional sensing by CodY does contribute to preventing growing cells from sporulating but its effectiveness in doing so is principally seen under conditions when cellular GTP levels are expected to be especially high.

B. subtilis has five related histidine kinases (members of the IIIB class) that are potentially capable of phos- 
phorylating SpoOF and feeding phosphoryl groups into the relay (Stephenson and Hoch 2002). Previous evidence has led to the view that at least four of the kinases, KinA, $\mathrm{KinB}$, KinC, and KinD, contribute to phosphorylation of SpoOF (Jiang et al. 2000). Our discovery that sporulation can be triggered by activation of the phosphorelay during growth provides a new way of assessing the role of class IIIB kinases in sporulation. The results showed that KinA, KinB, and KinC behaved in a sharply different manner than did KinD and KinE, with the former but not the latter being capable of triggering sporulation. Because the results with KinD and KinE were negative (i.e., a failure to trigger sporulation), we cannot exclude the possibility that our constructs were ineffective in elevating the levels of these kinases but not the other three. Nevertheless, the simplest interpretation of our results is that SpoOF is not the normal substrate for KinD and KinE.

Successful entry into sporulation requires tight coordination between chromosome duplication and asymmetric division (Piggot and Losick 2002). Cells that have begun to sporulate must complete a final round of DNA replication so that the early-stage sporangium contains two, and only two, copies of the chromosome, one that is segregated to the forespore and the other to the mother cell. Because the initiation of replication and the rate of growth are closely coordinated, cells that have been triggered to sporulate under conditions of nutrient depletion are expected to cease initiating new rounds of replication or at least do so at a greatly reduced rate. Viewed in light of these considerations, it might seem surprising that cells in the mid-exponential phase of growth in rich medium, which are expected to have multiple replication forks, can be triggered to undergo rapid and efficient sporulation. We therefore suspect that Spo0A P activates an as yet unrecognized mechanism that allows chromosome duplication to reach completion but prevents new rounds of replication from commencing. A checkpoint has been described that delays sporulation in response to conditions that perturb DNA replication (Burkholder et al. 2001). The checkpoint is mediated by a specific inhibitor of KinA and KinB called Sda, whose synthesis is negatively controlled by the replication initiation protein DnaA. It seems unlikely, however, that Sda can provide a full explanation for the mechanism by which new rounds of replication are blocked when sporulation is triggered by KinA in that the function of Sda is to inhibit KinA and KinB, not replication. Also, sporulation was induced as efficiently with KinC as with KinA and KinB.

Finally, our results underscore a long-standing mystery: What is the precise mechanism by which nutrient limitation triggers sporulation? CodY cannot be the only sensor, because mutants lacking the GTP-responsive protein do not undergo massive sporulation during growth (Ratnayake-Lecamwasam et al. 2001). It is sometimes assumed that sporulation is triggered by as yet unidentified ligands that activate KinA or KinB under conditions of nutrient limitation (Stephenson and Hoch 2002). However, we have shown that KinA, KinB, and
KinC are capable of triggering sporulation when nutrients are in abundance. Yet other proteins that are believed to have a role in governing entry into sporulation are the transcriptional regulators $\mathrm{AbrB}, \mathrm{Hpr}, \sigma^{\mathrm{H}}$, and SinR and the quorum-sensing peptide CSF (Piggot and Losick 2002). Conceivably, and as proposed previously (Hoch 1993), the decision to sporulate is a composite consequence of multiple and partially redundant pathways that sense nutrient limitation and cell population density and feed these signals into the phosphorelay and the positive feedback loop that governs the synthesis and phosphorylation of SpoOA.

In summary, we have succeeded in triggering rapid and massive sporulation during exponential-phase growth in rich medium by a strategy based on artificial activation of the phosphorelay that governs phosphorylation of Spo0A. We propose that the phosphorelay is part of a regulatory circuit that causes SpoOA protein and activity to increase gradually, and that entry into sporulation requires a slow increase in Spo0A P levels. Progressive accumulation of Spo0A P allows genes that respond to a low level of Spo0A P to be switched on or off prior to genes that respond at a high threshold level of the phospho-protein.

\section{Materials and methods}

\section{Strain construction}

The parent strain for all experiments was B. subtilis strain PY79 (Youngman et al. 1983). Strains used in this study are listed in Supplementary Table S1.

\section{Plasmid construction}

A description of the plasmids used can be found in the Supplemental Material.

\section{General methods}

Media, culture conditions, preparation of competent cells, preparation of chromosomal and plasmid DNA, assays of sporulation efficiency, and assays of $\beta$-galactosidase activity were as previously described (Fujita and Losick 2002). Cells were grown in CH medium (Sterlini and Mandelstam 1969). Sporulation in the wild type was induced by suspending exponential-phase cells in SM medium (Sterlini and Mandelstam 1969).

\section{Fluorescence microscopy}

Fluorescence microscopy was performed as described previously (Fujita and Losick 2002).

\section{Immunoblot analysis}

Immunoblot analysis was performed as described previously (Fujita and Losick 2002). Polyclonal anti-Spo0A antibodies (Fujita 2000) were used for the detection of Spo0A and Spo0A*. Polyclonal GFP antibodies (Rudner and Losick 2002) were used for the detection of GFP-tagged KinA. Polyclonal $\sigma^{\mathrm{A}}$ antibodies (Fujita 2000) were used for the detection of $\sigma^{\mathrm{A}}$. 


\section{Acknowledgments}

We thank D. Rudner, D. Kearns, J.E. Gonzalez-Pastor, and A.L. Sonenshein for strains and plasmids, and S. Ben-Yehuda, A.D. Grossman, M. Laub, L. Shapiro, A.L. Sonenshein, P. Stragier, and members of the Losick lab for helpful comments and discussions. This work was supported by NIH grant GM18568 to R.L.

\section{References}

Ben-Yehuda, S., Rudner, D.Z., and Losick, R. 2003. RacA, a bacterial protein that anchors chromosomes to the cell poles. Science 299: 532-536.

Branda, S.S., Gonzalez-Pastor, J.E., Ben-Yehuda, S., Losick, R., and Kolter, R. 2001. Fruiting body formation by Bacillus subtilis. Proc. Natl. Acad. Sci. 98: 11621-11626.

Britton, R.A., Eichenberger, P., Gonzalez-Pastor, J.E., Fawcett, P., Monson, R., Losick, R., and Grossman, A.D. 2002. Genome-wide analysis of the stationary-phase $\sigma$ factor $(\sigma-\mathrm{H})$ regulon of Bacillus subtilis. J. Bacteriol. 184: 4881-4890.

Burbulys, D., Trach, K.A., and Hoch, J.A. 1991. Initiation of sporulation in B. subtilis is controlled by a multicomponent phosphorelay. Cell 64: 545-552.

Burkholder, W.F., Kurtser, I., and Grossman, A.D. 2001. Replication initiation proteins regulate a developmental checkpoint in Bacillus subtilis. Cell 104: 269-279.

Fabret, C., Feher, V.A., and Hoch, J.A. 1999. Two-component signal transduction in Bacillus subtilis: How one organism sees its world. J. Bacteriol. 181: 1975-1983.

Fujita, M. 2000. Temporal and selective association of multiple $\sigma$ factors with RNA polymerase during sporulation in Bacillus subtilis. Genes Cells 5: 79-88.

Fujita, M. and Sadaie, Y. 1998. Feedback loops involving Spo0A and $\mathrm{AbrB}$ in in vitro transcription of the genes involved in the initiation of sporulation in Bacillus subtilis. J. Biochem. (Tokyo) 124: 98-104.

Fujita, M. and Losick, R. 2002. An investigation into the compartmentalization of the sporulation transcription factor $\sigma^{\mathrm{E}}$ in Bacillus subtilis. Mol. Microbiol. 43: 27-38.

. 2003. The master regulator for entry into sporulation in Bacillus subtilis becomes a cell-specific transcription factor after asymmetric division. Genes \& Dev. 17: 1166-1174.

Fujita, M., Gonzalez-Pastor, J.E., and Losick, R. 2005. High- and low-threshold genes in the Spo0A regulon of Bacillus subtilis. J. Bacteriol. 187: 1357-1368.

Gonzalez-Pastor, J.E., Hobbs, E.C., and Losick, R. 2003. Cannibalism by sporulating bacteria. Science 301: 510-513.

Hoch, J.A. 1991. spo0 genes, the phosphorelay, and the initiation of sporulation. In Bacillus subtilis and other Grampositive bacteria: Biochemistry, physiology, and molecular genetics (eds. A.L. Sonenshein et al.), pp. 747-755. American Society for Microbiology, Washington, D.C.

Hoch, J.A. 1993. Regulation of the phosphorelay and the initiation of sporulation in Bacillus subtilis. Annu. Rev. Microbiol. 47: 441-465.

Ireton, K., Rudner, D.Z., Siranosian, K.J., and Grossman, A.D. 1993. Integration of multiple developmental signals in $\mathrm{Ba}$ cillus subtilis through the Spo0A transcription factor. Genes \& Dev. 7: 283-294.

Jiang, M., Shao, W., Perego, M., and Hoch, J.A. 2000. Multiple histidine kinases regulate entry into stationary phase and sporulation in Bacillus subtilis. Mol. Microbiol. 38: 535542.

Lopez, J.M., Marks, C.L., and Freese, E. 1979. The decrease of guanine nucleotides initiates sporulation of Bacillus subti- lis. Biochim. Biophys. Acta. 587: 238-252.

Lopez, J.M., Uratani-Wong, B., and Freese, E. 1980. Catabolite repression of enzyme synthesis does not prevent sporulation. J. Bacteriol. 141: 1447-1449.

Molle, V., Fujita, M., Jensen, S.T., Eichenberger, P., GonzalezPastor, J.E., Liu, J.S., and Losick, R. 2003a. The Spo0A regulon of Bacillus subtilis. Mol. Microbiol. 50: 1683-1701.

Molle, V., Nakaura, Y., Shivers, R.P., Yamaguchi, H., Losick, R., Fujita, Y., and Sonenshein, A.L. 2003b. Additional targets of the Bacillus subtilis global regulator CodY identified by chromatin immunoprecipitation and genome-wide transcript analysis. J. Bacteriol. 185: 1911-1922.

Perego, M. and Hoch, J.A. 2002. Two-component systems, phosphorelays, and regulation of their activities by phosphatases. In Bacillus subtilis and its closes relatives: From genes to cells (eds. A.L. Sonenshein et al.), pp. 473-481. American Society for Microbiology, Washington, D.C.

Piggot, P.J. and Losick, R. 2002. Sporulation genes and intercompartmental regulation. In Bacillus subtilis and its closest relatives: From genes to cells (eds. A.L. Sonenshein et al.), pp. 483-518. American Society for Microbiology, Washington, D.C.

Predich, M., Nair, G., and Smith, I. 1992. Bacillus subtilis early sporulation genes kin $A$, spoOF, and spoOA are transcribed by the RNA polymerase containing $\sigma^{\mathrm{H}}$. J. Bacteriol. 174: 27712778.

Ratnayake-Lecamwasam, M., Serror, P., Wong, K.W., and Sonenshein, A.L. 2001. Bacillus subtilis CodY represses early-stationary-phase genes by sensing GTP levels. Genes \& Dev. 15: 1093-1103.

Rudner, D.Z. and Losick, R. 2002. A sporulation membrane protein tethers the pro- $\sigma^{\mathrm{K}}$ processing enzyme to its inhibitor and dictates its subcellular localization. Genes \& Dev. 16: $1007-1018$.

Sonenshein, A.L. 2005. CodY, a global regulator of stationary phase and virulence in Gram-positive bacteria. Curr. Opin. Microbiol. 8: 203-207.

Stephenson, K. and Hoch, J.A. 2002. Evolution of signalling in the sporulation phosphorelay. Mol. Microbiol. 46: 297-304.

Sterlini, J.M. and Mandelstam, J. 1969. Commitment to sporulation in Bacillus subtilis and its relationship to development of actinomycin resistance. Biochem. J. 113: 29-37.

Stragier, P. and Losick, R. 1996. Molecular genetics of sporulation in Bacillus subtilis. Annu. Rev. Genet. 30: 297-341.

Strauch, M.A., Wu, J.J., Jonas, R.H., and Hoch, J.A. 1993. A positive feedback loop controls transcription of the spoOF gene, a component of the sporulation phosphorelay in Bacillus subtilis. Mol. Microbiol. 7: 967-974.

Youngman, P.J., Perkins, J.B., and Losick, R. 1983. Genetic transposition and insertional mutagenesis in Bacillus subtilis with Streptococcus faecalis transposon Tn917. Proc. Natl. Acad. Sci. 80: 2305-2309. 


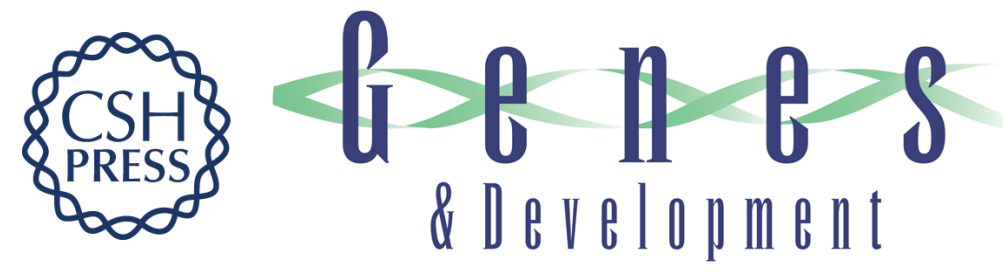

\section{Evidence that entry into sporulation in Bacillus subtilis is governed by a gradual increase in the level and activity of the master regulator Spo0A}

Masaya Fujita and Richard Losick

Genes Dev. 2005, 19:

Access the most recent version at doi:10.1101/gad.1335705

Supplemental http://genesdev.cshlp.org/content/suppl/2005/09/15/19.18.2236.DC1

Material

References This article cites 28 articles, 15 of which can be accessed free at:

http://genesdev.cshlp.org/content/19/18/2236.full.html\#ref-list-1

License

Email Alerting Receive free email alerts when new articles cite this article - sign up in the box at the top

Service right corner of the article or click here.

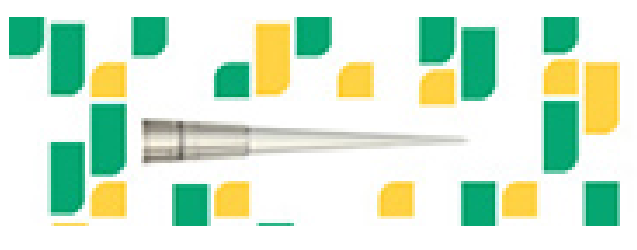

Focused on your science. 